\title{
THE NETWORK DYNAMICS OF STATUS: ASSIMILATION AND SELECTION
}

\section{AUTHORS:}

\section{Vanina Jasmine Torlò*}

Principal Lecturer in Strategic Management, Department of Systems Management and Strategy, Faculty of Business, University of Greenwich, Old Royal Naval College, Park Row, London SE10 9LS, UK

E-mail: V.J.Torlo@greenwich.ac.uk

\section{Alessandro Lomi}

Interdisciplinary Institute of Data Science, University of Lugano, Switzerland E-mail: alessandro.lomi@gess.ethz.ch

Acknowledgements: We thank Tom Snijders and Christoph Stadtfeld for comments and advice on earlier versions of the manuscript. Alessandro Lomi is grateful to the Chair of Computational Social Science and the Chair of Social Networks in the Department of Humanities, Social and Political Sciences of the ETH Zürich for hospitality and support during part of this work.

*Corresponding author 


\begin{abstract}
Using longitudinal data that we have collected on friendship and advice relations in a cohort of MBA students, we examine how status affects the dynamics of network ties among peers. Estimates of Stochastic Actor-Oriented Models (SAOMs) suggest that status is a consequence of network ties because over time the level of status attributed to individual students by other students tends to the average level of status attributed to their network partners - a phenomenon we call status assimilation. Status is also an antecedent to network ties because it affects partner selection decisions giving rise to distinct forms of social attachment. We find that both network-based processes of status assimilation, as well as status-based processes of social selection are present, but vary subtly yet significantly across network domains. Students tend to the average level of status of their friends, but not that of their advisors. High-status students are more active in the friendship network, but more popular in the advice network. We find evidence of performance homophily rather than status homophily: students with similar grades are more likely to exchange friendship and advice ties. High status students tend to be more central in the advice network, but status attributions spill over through friendship, rather than advice relations. The study documents how the relation between social status and social networks varies both over time, as well as across network domains. The study also demonstrates the importance of accounting for multiplexity - the tendency of a network to operate through another.
\end{abstract}

Keywords: Academic performance; Education; Network dynamics; Peer Effects; Schooling; Social influence; Social networks; Social selection; Social status; Stochastic Actor Oriented Models; 


\section{INTRODUCTION}

Because: "Status-based social forces often threaten to break the ties between increasingly differentiated members of a group thus putting at risk the survival of the collectivity" (Bothner, Stuart and White, 2004: 262) it is hard to think of a more consequential sociological problem than establishing the causal relation linking change in social status and change in social networks.

This relation has been the object of considerable debate in recent studies of organizations and social networks (Chen et al., 2012; Sauder, Lynn and Podolny, 2012). The direction of causality, however, remains difficult to ascertain unambiguously because of the tendency of "status-based social forces" to be both antecedents, as well as consequences of network ties. Status is an antecedent of network ties in that it affects individual preferences for social interaction giving rise to distinct forms of preferential attachment and social exchange (Blau, 1964; McPherson and Smith-Lovin, 1987). For example, high status individuals are typically more likely to receive recognition for their achievements and attract valuable resources. As a consequence, high status individuals tend to be considered more desirable partners and, therefore, are more likely to attract network ties (Rossman, Esparza and Bonacich, 2010).

Status is also a consequence of social networks because of its inherent tendency to spill over or "leak" - through social relations (Podolny, 2001). For example, Kilduff and Krackhardt (1994) argue that the status and prominence of network partners increase the reputation for performance of the focal individual thus making him or her more likely to attain a higher level of prominence and status among peers. In more general terms, extant research shows that individuals connected to high status alters are typically viewed more favorably and are therefore attributed even higher status (Podolny, 1993; Thye, 2000). Conversely, the status of individuals tied to low-status alters is frequently discounted and devalued (Blau 1964). One observable macro-outcome of these self-reinforcing micro-mechanisms is social stratification or status ordering (Fiske, 2010).

Contemporary research recognizes that the interdependence between social status and social networks depends on the fact that: "For any given bounded group, we can conceive its (informal) status hierarchy as a web of deference relations among its members" (Sauder, Lynn 
and Podolny, 2012). Deference relations signal - but simultaneously produce and reproduce interpersonal status differences.

In this paper we seek to advance this line of inquiry by showing how an explicitly network approach reveals subtle aspects of the dynamic relation linking social status and social networks. Our work complements and extends prior research in three ways. First, we reconstruct status as deriving from the accumulation of gestures of deference as expressed by subjects at different time points (Gould, 2002). Treating status as the aggregate outcome of a decentralized system of social perceptions, reduces the possibility that status be affected by strategic manipulations of network positions, and provides a direct measure of participants' perceptions of others (Martin, 1998). Second, while much empirical research on status has been conducted within the boundaries of one specific network domain, we examine how the antecedents and consequences of status are contingent on - and vary across different network domains (White, 1992). More specifically, we examine how the general principle of assimilation according to which: "network actors adapt their own individual characteristics to match those of their own social neighborhood" (Steglich et al., 2006: 48) varies across different kinds of social networks. Third, we specify and estimate a recently derived class of Stochastic Actor-Oriented Models (SAOMs) allowing joint representation of change in social status and network ties (Snijders, van de Bunt and Steglich, 2010). While extensive empirical research is available on how the level of individual status and the presence, absence or strength of network ties might be related, little or no research is available on how change in status affects change in network ties over time (Sauder, Lynn and Podolny, 2012). In this paper we examine the joint dynamics linking change in network ties and change in individual status.

The empirical context that sets the stage of our study is provided by longitudinal data that we have collected on a cohort of students enrolled in a professional program offered by an elite Italian university. We focus on network of advice and friendship relations because prior research has demonstrated that these network domains tend to be sociologically relevant in general (Kilduff, and Krackhardt, 2008) - but are particularly meaningful in educational settings (Kilduff, 1990) where collaborative and competitive processes often operate through social networks. Friendship and advice networks are also useful because they represent good examples of expressive and instrumental relations, respectively. This is an important distinction 
in our case because: "Instrumental network ties are those developed for information, advice, and resource exchanges that are needed to accomplish tasks. Expressive ties are ties carrying either positive or negative emotions that are not necessarily task-related" (Yuan and Gay, 2006: 1062). Both type of ties are relevant to the overall educational attainment process (Akerlof and Kranton, 2002).

We adopt a common definition of status as the accumulation of acts of deference (Podolny and Phillips, 1996). In our context, acts of deference are related to contribution to learning as perceived and reconstructed by respondents. To foreshadow the discussion that we develop in the empirical part of the paper, change in the status attributed to students in our sample is reconstructed as change in the aggregate number of reported acts of deference received during the observation period. Therefore, a student who is attributed high status by peers will be central in the network of deference relations. The relation we postulate between attributed status and network centrality is common in sociological studies of status (Faris and Felmlee, 2011).

The research context that frames our study is particularly useful because it allows direct observation of the social processes of core theoretical interest while at the same time facilitating the control of typically unobservable factors linked to individual qualities that may confound the causal relation linking change in network ties to change in attributions of social status.

\section{STATUS AS ANTECEDENT AND CONSEQUENCE OF SOCIAL NETWORKS}

Social status and social networks stand in a dynamic relation of mutual constitution: change in one establishes the conditions for change in the other. Most available studies of social status tend to ignore interlocked processes of network and status change to espouse an "ego-centric" view of status change as a consequence of change in individual traits or behavior. More recently an "alter-centric" view of status has emerged based on the observation that "deference cannot be seized by an actor but rather is something that is awarded by others" (Sauder, Lynn and Podolny 2012: 273). In this study, we articulate this view in a professional educational setting where status differences among students emerge through the accumulation of reported acts of deference and attributions, and where networks involve advice and friendship relations observed among students (Lomi, Snijders and Torló, 2011). Longitudinal 
studies of social status and social networks typically examine change only in one direction without accounting for the fact that status may be both a consequence and an antecedent of social networks.

Evidence in support of the view that status is a consequence of network ties is extensive. For example, in their reanalysis of the classic Sampson's (1968) monastery data set, Bonacich and Lloyd (2004) show that a positive connection with a high status alter increases ones status and, symmetrically, that positive connection to a low status alter decreases one's own status. Rossman, Epsaraza and Bonacich (2010) show that movie stars with prestigious costars are more likely to be nominated for an Academy Award. More generally, current research on social status accepts that individual status is influenced by the status of network associates (Sauder, Lynn, and Podolny, 2012). Actors connected to high status alters are typically viewed more favorably and are therefore attributed higher status (Podolny, 1993). In more general terms, these studies suggest that signals of status are transmitted by and through network ties (Kilduff and Krakhardt, 1994; Podolny, 2005). Equally important is the evidence that this literature contributes to the view of networks not only as pipes for the flow of resources, but as interpretive lenses that support inference about unobservable quality of potential partners (Podolny, 2001).

Similarly extensive is research portraying status as an antecedent, rather than a consequence of network ties (Borgatti and Foster, 2003; Brass, Galaskiewicz, Greve and Tsai, 2004). For example, in their study of advice relations among lay judges in the Commercial Court of Paris, Lazega, Mounier, Snijders and Tubaro (2011) treat status differentials as causal factors in the formation and change of advice ties. Confirming Blau's insight (1964), Lazega, Mounier, Snijders and Tubaro (2011) find that status is exchanged for advice: as a consequence the structure of the advice network connecting the judges is shaped by the tendency of high-status judges to attract a significant larger number of network ties.

Status not only affects the individual propensity of actors to receive or send network ties, but also the kind of "alters" that are more likely to stand at the receiving end of the relation. In other words, status may also be analyzed in terms of its dyadic consequences - not only in terms of "who forms ties," but also of "who forms ties with whom." Studies in which status is measured more conventionally in terms of an individual attribute (e.g., as "marital" status, 
"educational" status, or "occupational" status) recording membership in an exogenous category tend to support classic "status homophily" arguments (Lazersfield and Merton, 1954). Status homophily posits that individuals of similar status, i.e., members in the same sociodemographic category, are more likely to be related (McPherson, Smith-Lovin and Cook, $2001)^{1}$. Because social categories are also discursive entities, these results say little about the effects of category membership per se and may be interpreted only with reference to the "range in social meanings by which individuals understand and construct their world" (Pachucki and Breiger, 2010: 206). These considerations shift the focus of attention from social classification to processes of social construction of the status value attached to nominal characteristics, and of emergence of shared status beliefs (Mark, Smith-Lovin and Ridgeway, 2009).

Studies based on a relational view of status as resulting from individual acts of deference and affiliation (Sauder, Lynn and Podolny 2012) have reported variable - and partly contrasting results. This may be due to the fact that affiliation-based status resulting from acts of deference produces "multifaceted and encompassing" information (Podolny, 1993: 834) which typically requires assumptions about the distribution of individual abilities to read status signals. Results of earlier studies supporting hypotheses of status homophily (Chung, Singh, and Lee, 2000) tend to co-exist with results produced by more recent studies arguing and showing that both higher-status as well as lower-status actors may find it beneficial to establish statusheterophilous ties (Smith, Menon, and Thompson. 2012). These more recent results suggest that status-dependent social selection processes may produce very different equilibrium outcomes: without explicit reference to situational factors it is difficult to predict a priori whether segregating mechanisms of status homophily, or blending mechanisms of status heterophily will dominate.

The arrival point of our discussion is that in available studies causality seems as likely to flow from status to the formation, maintenance and dissolution of network ties, as it is to flow in the opposite direction. To go beyond the simple acknowledgement of the problem, analysis of social status and social networks requires a framework sensitive to situational factors affecting the direction of the causal relation connecting them in specific relational contexts. In the

\footnotetext{
${ }^{1}$ We are using the term "category" because we want to avoid the confusion between "status" and "class" identified and discussed by Chan and Goldothorpe (2007).
} 
section that follows, we describe an empirical study that we have designed to address these concerns. Our emphasis on change and longitudinal network analysis allows us to illuminate the dynamic relation linking status and network ties. Our focus on co-evolutionary mechanisms helps us to articulate change in status and change in social networks as mutually constitutive processes.

\section{SETTING}

The empirical opportunity for examining the relation between change in social networks and change in social status is provided by data that we have collected on students enrolled in a fulltime master in business administration (MBA) program, in an élite Italian school for professional management education. Educational contexts provide ideal social setting for the study of status because - unlike formal organizations - students' behavior is rarely affected by pre-assigned roles, or by differences in formal hierarchical positions. As a consequence, the notion of "peer" is frequently used in educational settings to suggest the tendency of students to consider each other as living and sharing a similar experience. DiMaggio and Garip (2012) provide a comprehensive review of results on network effects produced by more recent research in the sociology and economics of education and in related literatures.

The full-time program we selected for study attracts students oriented toward managerial careers in private and public companies, consulting and service firms, and in the financial sector. Students come from a variety of backgrounds, but all have a proven record of academic achievement. Although they start the program without knowing each other, students spend a considerable amount of time in and out of the classroom - at least 8 hours a day during the first 12 months of the program. The program requires students to coordinate and collaborate on many activities such as gathering and analyzing data, preparing and delivering presentations, and preparing for case discussions.

The context of professional education is particularly useful to our purpose because an analysis of the co-dependence of interpersonal networks and individual status is likely to sustain more convincing results in situations where social networks as well as individual outcomes are constructed by a fixed set of social actors sharing contextual constraints. Also, the specific setting selected is relevant in terms of the more general issues that we want to address because programs in leading business schools are explicitly designed to emulate socialization and social 
learning processes similar to those of large professional companies. Because of the heavy course schedule and workload, MBA programs represents social settings in which individual achievement is mediated by a variety of social processes embedded in networks of advice and friendship relations (Kilduff, 1990). Consistent with classic insight on the role of social networks in the labor market (Granovetter, 1974), our field work demonstrates that MBA students in our sample are well aware of the opportunity provided by attending business schools to build a portfolio of social connections that may be mobilized in the future as their business careers unfold. As a result, we would expect processes of social influence and social selection to be particularly transparent in this empirical setting.

\section{RESEARCH DESIGN DATA AND METHODS}

Data

We followed a cohort of 75 students enrolled in a full-time master in business administration in an élite Italian school for professional management education. The cohort is a meaningful social unit in our case because students enrolled in the program were not subdivided into different classes or streams, nor were they assigned to permanent teams or work groups. The data set we analyze is the result of a three-wave network-panel design. The overall observation period is defined by the entire duration of the MBA program dedicated to coursework. The program starts in November. The observation points are roughly equally spaced (March, July, and November). A 5-month in-company project concludes the program.

We collected information on (i) individual attributes, (ii) network ties among students, and (iii) students' status (as defined below). Building on prior research on intra-personal networks we selected two distinct relational contents to define network ties: friendship and advice. Students in the cohort occasionally work in groups - but they are not assigned to permanent groups to encourage socialization and exposure to different alters. Their performance is evaluated individually. A questionnaire was administered at the beginning of the study to verify the absence of prior social relations between the students. Figures 1a and 1b provide a graphical illustration of the evolution of the corresponding networks during the period of observation. The black squares in the matrices record the presence of a network tie between the corresponding row and column element. While the overall network densities do not change much over time, the various local configurations of network ties exhibit considerable local 
variations. This is illustrated by changes in the local neighborhoods highlighted in the figures. The next section provides a complete description of the variables and measures used.

--- [Insert Figure1a and Figure1b about here] ---

\section{Variables and measures}

We collected information on a variety of individual attributes to control for socio-demographic differences. Descriptive statistics are reported in Table 1. To complete the program students are required to complete a total of 32 exams. The maximum grade is thirty and eighteen is the lowest passing grade. Average overall performance is 25.98 (s.d. = 1.59, range 20-30). We received information on grades directly from the MBA program office.

\section{--- [Insert Table 1 about here] ---}

We collected information on social networks through questionnaires administered individually to each student in three distinct occasions (100\% response rate in each of the three waves). Building on extensive prior research about social networks in academic and other organizations, we selected two distinct relational contents: friendship and program-related advice (Cross et al., 2001; Kilduff, 1992). To collect relational information we relied on the so called "roster method" (Kilduff and Krackhardt, 2008). Each respondent ('ego') was presented with a complete list of names and asked to report the presence of the specified relation with other class members. For friendship we asked respondents to indicate the names of classmates ('alters') with whom they felt they had developed meaningful social ties outside the specific context of the program. The questionnaire specified examples of joint social activities that might be considered as signals of friendship such as going to the movies, having dinner, playing football or going shopping. For advice relations, we asked respondents to indicate the names of other students whom they recurrently consulted for help and support on course-related tasks. The questionnaire included examples of concrete activities that might signal the presence of advice relations such as asking for class notes, borrowing books, calling for help to solve difficult homework problems, and discussing course material. The questions were framed in a non-judgmental manner. Respondents were reassured that there were no right or wrong answers, that their privacy would be protected and, and that they were completely free to select as many or few names as they wished. In the first panel, we also verified the existence of ties 
existing before the beginning of the program, but none were reported. The questions about friendship and advice ties were asked identically on each of the three data collection occasions. At each observation point the network questionnaires generated two square adjacency matrices of size 75. In each matrix the generic cell $x_{i j k t}$ is equal to 1 if row actor $i$ indicated the presence of relation $k$ with column actor $j$ at time $t$, otherwise $x_{i j k t}=0$. In relational observation schemes, the number of observations in each network is typically considered equal to the number of pairs of actors, i.e., $75 \times 74=5550$. Hence the analysis of each network is based on $16,650(5550 \times 3)$ non-independent observations. Table 2 reports the main descriptive statistics of the two networks. While the average degree does not change much over time, the presence of friendship and advice ties exhibits considerable fluctuation. Friendship and advice ties overlap somewhat: the density of the intersection between advice and friendship ties is approximately $3 \%(0.028)$. Because the density of the advice network is approximately $5 \%(0.055)$, almost $50 \%$ of advisors are also friends.

--- [Insert Table 2 about here] ---

Table 3 reports the change statistics of the networks of friendship and advice, respectively.

--- [Insert Table 3 about here] ---

The fundamental actor-specific dependent variable - students' status- is based on information contained in a third network. In the same three data collection occasions we asked students to identify names of classmates whom they felt contributed most significantly to their own personal learning experience during the program. Information on the content of this third network domain was explicitly collected in order to capture expressed deference relations among students - the social basis of status. Clearly, individuals cannot control deference through decisions or acts of will (Ridgeway 1984: 62). Rather, deference is granted by others through deference-conferring gestures (Gould 2002). The building blocks of a group's status hierarchy is the accumulation of deference-conferring gestures linking members to one another so that an actor occupies a high-status position if members of the group treat her with deference (Lynn et al., 2009). This is particularly the case in social settings that are not structured by an exogenous hierarchy of formal positions. In the case we examine, acts of deference are represented by the acknowledgment of others' contribution to the personal learning experience during the program. The question was designed to reconstruct a notion of status consistent with 
Magee and Galinsky's definition of social status as (2008: 353): "The extent to which an individual or group is respected or admired by others." More importantly, our concept of status as an aggregate perception is consistent with Martin's (1998) approach to the analysis of power in naturally occurring communities. The unique advantage of conceptualizing status as the outcome of an aggregate perception from individual attributions is that in this way respondents cannot strategically manipulate their own status. We have, in other words, a direct measure of people's perception of status (Martin, 1998; 198).

Our approach to status is consistent with the "alter-centric" definition of status as conferred by acts of deference, and is particularly appropriate in the context of our study. However, the measure we propose is somewhat inconsistent with a strict interpretation of Stochastic Actor Oriented Models (SAOMs) - choice-based models where actors are assumed to control only their outgoing ties and to change them based on a multinomial choice probability model (Block, Stadtfeld and Snijders, 2017). Strictly speaking, in this framework actors cannot "choose" their own status, although actors may prefer a higher to a lower status. To the extent they value status, however, actors may try to change the behavior under their direct control to attract deference. For this reason, the results we report below are best interpreted in terms of probabilistic tendencies - or as a heuristic solution to a choice problem rather than the unique consequence of a sequence of utility-maximizing decisions. To obtain the status measure we constructed three adjacency matrices of size 75 (one for each data collection occasion) where the generic cell $x_{i j}$ is equal to 1 if row actor $i$ has indicated the presence of a relation of "deference" with column actor $j$, otherwise $x_{i j k}=0$. Then we used these three matrices to compute the Indegree centrality score for each respondent, which represents our relational measure of status - an approach to status that is increasingly common in current empirical research (Lazega et al., 2011). The mean (and standard deviation) of the Indegree centrality in the three-time period considered are - respectively: 4.83 (5.29) in T1; $5.76(5.25)$ in $\mathrm{T} 2$, and 6.31 (5.12) in T3.

MBA students compete intensely to be included in the top percentile. Academic performance is treated as a signal of their commitment, sense of duty and competence - qualities valued both by potential employers, as well as potential business partners. In our sample, a student has high status to the extent that many others acknowledge that she has contributed significantly to their 
own learning experience in the context of the program. The view of status underlying the measure that we adopt is consistent with commonly held view of status as resulting from individual acts of deference - and hence as a relational asset (Bothner et al. 2014). We rely on current theoretical understanding of status as a: "position in a social hierarchy that results from accumulated acts of deference" (Sauder, Lynn, \& Podolny, 2012: 268). In the analysis we report in the empirical part of the paper we do not model directly processes of status construction (i.e., the "flow" of status through network ties) underlying the accumulation of status as an asset. See Podolny and Phillips (1996) for a similar distinction between status as a "stock" or as a "flow."

\section{Empirical model specification and estimation}

In the empirical part of the paper we rely on a class of stochastic actor-oriented models (SAOMs) introduced by Snijders (2001). SAOMs are probability models for network change that assume that actors decide which of their outgoing ties to change according to a multinomial discrete choice probability model. A technical treatment of SAOMs may be found in Snijders (2005). An introductory guide to the specification and estimation of SAOMs may be found in Snijders, van de Bunt and Steglich (2010). Interested readers are referred to Snijders' recent comprehensive review (2017).

The feature that makes SAOMs uniquely useful for our current purposes is that they allow joint representation of network-based processes of social influence (underlying change in the level of individual status), and social selection (underlying change in network ties determined by interpersonal similarities and differences in status) (Lewis, Gonzalez, and Kaufman, 2012). More specifically, SAOMs allow specification of empirical models admitting the possibility of dynamic feedback connections linking change in individual status and change in network structure (Steglich, Snijders, and Pearson, 2010). We adopt the recently derived model for multiplex relation proposed by Snijders, Lomi and Torló (2013). This model allows joint representation of multiple networks - a feature that helped us to model friendship and advice relations as codependent.

In the model we estimate in the empirical part of the paper, we use average status similarity as our main measure of social influence. Suppose that $z$ is the relevant measure of status, then

$$
\operatorname{sim}_{i j}^{z}=\left(1-\left|z_{i}-z_{j}\right| / \Delta_{z}\right)
$$


average status similarity between an actor $i$ and his network partners is defined as:

$x_{i+}^{-1} \sum_{j} x_{i j}\left(\operatorname{sim}_{i j}^{z}-\overline{\operatorname{sim}^{z}}\right)$, where $x_{i+}$ is the outdegree of actor $i$ and with $\Delta_{z}=\max _{i j}\left|z_{i}-z_{j}\right|$

representing a (scaled) measure of average status similarity ${ }^{2}$. A significantly positive parameter associated with the average similarity effect thus defined may be interpreted as evidence of a tendency toward status similarity between network partners. An alternative interpretation of positive average similarity effect would be that status conferred to ego tends to become more similar to the status conferred to his or her network partners - an outcome that would be consistent with the assimilation principle discussed by Steglich et al. (2006). Alternative measures that may be used to represent tendencies toward similarity between networks associates produced by social influence are discussed in Snijders, van de Bunt and Steglich $(2010)^{3}$.

Parameter estimates of SAOMs may be obtained via Markov Chain Monte Carlo methods as explained in Snijders et al. (2007), and implemented in the RSiena software package (Ripley et al. 2016). Table 4 summarizes the network effects included in the objective functions specifying the network statistics and their interpretation in the context of advice relations.

-- Insert Table 4 about here-

Following recommended best practice for the analysis of network dynamics using SAOMs (Snijders and Steglich, 2015) we implement a Monte Carlo simulation-based approach to evaluate the goodness of fit of the model - i.e., the model's ability to reproduce the data. Based on the empirical estimates we generate a distribution of networks out of which we extract a random sample of 1000 networks. We then compare the data with simulated network distribution implied by the estimates using the so called violin plots (Hintze and Nelson 1998) which combine the information contained in boxplots and a kernel density plots. Additional

\footnotetext{
${ }^{2}$ Clearly, if $\mathrm{x}_{\mathrm{i}+}=0$, then similarity score of actor $i$ is $=0$ because an actor with no network partners is assumed not to be susceptible to network influence.

${ }^{3}$ Similarly to Snijders, van de Bunt and Steglich (2010), in the empirical part of the paper we use average similarity because preliminary score-type tests indicate that alternative measures of similarity that may be adopted do not provide equally useful characterization of processes of social influence in our sample. The logic of score-type tests in SAOM is discussed in Snijders et al. (2007).
} 
information on this goodness of fit diagnostic approach for SAOMs may be found in Ripley et al. (2016).

\section{RESULTS}

We start by presenting the results of QAP correlations (10,000 permutations) that we have computed on the three networks (friendship, advice and deference) across the three periods under investigation. Table $\mathbf{5}$ shows that all the three networks are quite stable over time: within correlations are in fact very similar. It is also worth noting that the correlation between the advice and friendship networks is relatively weak, while the deference network is more strongly associated with the advice network. However, the correlation between the deference and advice networks is never very strong, indicating that respondents tend to distinguish between "advisers" and "people they defer to".

-- Insert Table 5 about here -

We now present a qualitative interpretation of the estimates, following which we narrow the focus of the analysis and provide a post-hoc numerical interpretation of the parameters of main theoretical interest. Table 6a reports the estimates of parameters in the evaluation function specifying how individual status changes as a function of individual attributes and status of network associates. For each network (friendship and advice) we estimated four models which we report in an increasing order of completeness and complexity of the underlying specification. The first model is a baseline ("trend only") model. The second model also contains the effects of the structural (i.e., network-based endogenous) network change mechanisms as well as factors that may affect individual status. The third model is more comprehensive and controls for a number of exogenous factors (control covariates) that may affect the network evolution. The fourth model (full) reports the complete set of estimates for the social influence and social selection functions. Finally, we report a fifth model (multiplex) which reports the determinants of individual status when simultaneously analysing the two networks under investigation (friendship and advice) in the context of a multiplex network analysis (Snijders, Lomi and Torló, 2013).

Results for average similarity reveal that the level of status attributed to an individual student by his or her peers tends to become similar to the level of status attributed to his or her network 
partners - i.e., to change in the direction of greater similarity (or to remain similar) to network partners. Interestingly, the effect is only significant for the friendship network (positive average similarity parameter). This result is also confirmed when considering the two networks simultaneously in a multiplex analysis. Table 6 a also shows that an important control variable such as ability does not have a significant effect on students' status. The non-significant estimates of the linear shape parameter for both networks suggest that there is no evidence for a systematic directional effect (either upward or downward). The non-significant (negative) estimates of the quadratic shape parameter suggest that the influence of network partners sufficiently explains the observed fluctuation in status, and that there are no residual tendency of regression toward the mean (see Snijders, van de Bunt and Steglich (2010) for indication about how to interpret the shape parameters in SAOMs). Note, however, that the pattern of signs in the estimates (positive linear and negative quadratic shape parameter) suggests the presence of self-balancing (or self-correcting) tendencies regulating the distribution of status attributions among students in the sample. This implies that the status of high-status individuals is unlikely to increase indefinitely, and in fact it may decline above a certain threshold implied by the estimates. This conclusion would be consistent with recent research on the contextual nature of the Matthew effect on the accumulation of social status (Bothner et al., 2010). In Table 6a the estimated rate parameters describe the average number of opportunities for change in students' status between measurement points. Estimates reveal that opportunities for change peak in the first period and decline in the second, suggesting a tendency of students' status to stabilize over time.

-- Insert Tables $6 \mathbf{a}$ and $6 \mathbf{b}$ about here -

Table $6 \mathbf{b}$ reports the estimates of parameters in equation (2) specifying processes of social selection driving change in network ties over time. In both networks, there is no evidence of status homophily (status similarity parameter): students with similar status are not significantly more likely to select similar others as friends and advisors. We find interesting differences across networks in the social selection implications of status. High status students are generally more active in the friendship network - possibly a consequence of their greater freedom to choose network partners (positive status ego parameter) and are sought after as advisors (positive status alter parameter) - a result that may be interpreted as an outcome of deference 
and a tendency towards status ordering. In both networks, the estimated rate parameters are larger in the first period than in the second, suggesting that networks of friendship and advice tend to become more stable over time.

Considered together, the results reported in Table $\mathbf{6 b}$ show that status affects the propensity to send or receive network ties in a way that is contingent upon the specific kind of network domains in which individuals participate. This highlights the importance of developing theories and models for improving our understanding of how the relation between social status and social networks might vary across social settings. As one would expect if students were fully informed about the aggregate distribution of status attribution in the classroom, status homophily does not seem to operate in the advice network: fully informed students would find it rational to go to advice to people with higher status. The positive alter effect of status provides further evidence of hierarchical ordering in the advice network (Agnessens and Wittek, 2012): other conditions equal, individuals prefer to choose high status advisers, i.e., advisers that attract deference from many others. This is clearly not the case in the friendship network: our third important results. High status students are very active in the friendship network. Together with the fact that the status homophily does not affect friendship ties, this result implies that the structure of the friendship network is not ordered by status. The estimates of the multiplex model confirm the results obtained on the individual networks.

The estimated effects of the control factors and structural network effects reported in Table $\mathbf{6 b}$ are generally consistent with intuition and prior research. The negative outdegree effect suggests that students avoid creating network ties that are not embedded in more complex local structures. The significant Reciprocity effect parameter indicates that students prefer friendship and advice relations that are reciprocated. Both the friendship and the advice seeking networks are characterized by tendencies toward local hierarchical ordering as suggested by the positive transitivity and negative 3-cycles parameters. In addition, the Popularity of alter effect is included to control for the tendency of students who receive many friendship and advice ties to receive further friendship and advice ties (tendency of the current popularity to "cause" future popularity). In the advice network, the positive parameter suggests that popular advisors tend to attract extra-incoming advice requests. 
We discuss the estimates of control variables reported in Table $\mathbf{6 b}$ only briefly and through illustrative examples. The main pattern is homophily, but differentiated with respect to the relation under consideration. The formation of friendship ties is facilitated by similarity in age, gender and nationality (positive age, gender and nationality similarity parameters) while the formation of advice ties is facilitated by similarity in academic background (positive academic background similarity parameter). Interestingly, in both network there is evidence for performance-based homophily (positive performance similarity parameter): students with similar performance are more likely to become friends and seek advice from each other. Yet, students with higher performance are less active in the friendship and advice from others (negative performance ego parameter) while they are more popular in the advice network (positive performance alter parameter).

The results described above are confirmed by the multiplex analysis which allows studying processes of social selection driving change in several relations simultaneously (in this paper: friendship and advice). Most interestingly, the multiplex analysis has allowed us directly to test the extent to which different relations can impinge on one another. In particular, we find support for a direct association (entrainment) between friendship and advice (positive Friendship: Advice and Advice: Friendship parameters): which indicates a strong tendency of friendship and advice ties to co-occur.

Tables 7a and $7 \mathbf{b}$ present the log-odds of increasing status compared to decreasing status as a function of the median status of friends (Table 7a) and advisors (Table 7b). Parameters are based on the Full Model as reported in Table 6a. Using the notation in (1), this is given by $f^{\text {beh }}(x, z+1)-f^{\text {beh }}(x, z-1)$, as dependent on the median status of the alters. For all the other variables, the mean values are used.

-- Insert Tables $7 \mathbf{a}$ and $7 \mathbf{b}$ about here --

Table 7a shows that having friends of high status (as we have defined it) leads to a significant upward drift in one's own status - what we have called a status assimilation effect. A status identical to one's own leads to a small downward drift at lower status levels and a bigger upward drift for high levels. Friends with higher status provide a significant upward pull, while friends with lower status only a small downward pull. For advisors (Table 7b) the picture is 
similarly interesting: advice received from low status students leads to a downward pull, while advice received from high status students leads to a significant upward pull. Thus, advice received from high-status advisors appears to be beneficial in more than one way. Advice and friendship ties seem to transmit status in ways that are subtly different - but clearly detectable. Clearly, these conclusions have to be taken with care as the average similarity effects are numerically large but not statistically significant.

Our discussion so far focused on the estimation and interpretation of individual parameters that are more strictly related to social selection and social influence processes as they pertain to status. This approach is consistent with the specification of a model based on micro-relational mechanisms and individual attributes, but containing no information on the global structure of the network. We now ask: how does the model based on the strictly local network mechanisms that we have specified reproduce global structural features of the network that was actually observed? We address this question in Figure 2 summarizing the results of a series of Monte Carlo simulation experiments based on the model implied by the estimates (corresponding to the full model as reported in Tables $6 \mathrm{a}$ and $6 \mathrm{~b}$ ). The analysis follows closely the approach to goodness of fit for SAOMs recommended by Snijders and Steglich (2015) and implemented in the Software RSiena (Ripley et al., 2016). Figure 2 reports the violin plots (Hintze and Nelson, 1998), for the indegree (Figure 2a) and outdegree (Figure 2b) distributions of the advice network. In Figure 2, the observed values are reported as red dots linked by a continuous red line, and associated to the corresponding counts, Dashed gray lines mark the upper and lower 2.5 percent values of the cumulative distribution. The plots in Figure 2 provide evidence of good fit for the actual changes observed in the data since the Monte Carlo Mahalanobis distance test p-values in both models are well above $0.05^{4}$ (Lospinoso, 2012). The tests fails to reject the hypotheses that the actual data and the data simulated on the basis of the model estimates are significantly different (or, more precisely, “distant”). The simulation analysis shows that our model of status as an antecedent and a consequence of social networks reproduces with high fidelity the main structural features of the network that was actually observed.

\footnotetext{
${ }^{4}$ The Mahalanobis distance test is based on the test statistic $D_{x}^{2}=\left(x-\mu_{x}\right)^{T} \Sigma_{x}^{-1}\left(x-\mu_{x}\right)$, where $\Sigma_{x}^{-1}=$ $\operatorname{Cov}(x)$, and $\mu_{x}=E(x)$. Of course $\left(\mu_{x}, \Sigma_{x}^{-1}\right)$ are not known. For this reason a Monte Carlo test based on simulation is used, and inference is based on the empirical cumulative density of $D_{x}^{2}$.
} 
-- Insert Figure 2 about here-

Following the same procedure, we computed the goodness of fit diagnostics for status attribution. The results of our simulation-based exercise is summarized in Figure 3 which reports the distribution of status in the sample The figure shows that the model reproduces well the (cumulative) distribution of status that was actually observed.

-- Insert Figure 3 about here-

When interpreted jointly, figures 2 ( $a$ and $b$ ) and figure 3 show that the model proposed is consistent with the observed in and out-degree distributions, and with the distribution of status that we actually observed. We are not aware of available studies attempting to link social status and social networks that have produced a comparable result in the context of a single model.

\section{DISCUSSION AND CONCLUSIONS}

Status differentiation is a near-universal social phenomenon (Gould, 2002). Status is systematically associated with differential access to resources, and individual differences in evaluation of quality and social legitimacy (Bothner, Podolny and Smith, 2011; Burt, 2013; Phillips and Zuckerman 2001; Salganik, Dodds and Watts, 2006). The extent to which these differences erode social solidarity and cohesion, or encourage social integration remains one of the central problems in sociological theories of status in organizations (Bothner, Stuart and White, 2004).

Our goal in this paper was to examine how the accumulation of status flows through the network ties that it contributes to create. Our findings demonstrate that the extent to which network ties transmit social status is contingent on the network domain under consideration: students tended to assimilate to the status of their friend, rather than the status of their advisors. How general this empirical conclusion might be is a matter for speculation. It could be, for example, than in a competitive educational setting network domains defined in terms of noninstrumental relations (like friendship) provide better support for the transmission of status perceptions. What is general beyond our context, however, is the importance of multiplexity in process of status construction and diffusion.

At the same time, we also found that status-based social selection varies across network domains: status makes students in our sample more active in their friendship networks, but 
more popular in the advice network. These results may seem obvious: to the extent that social networks act as social infrastructures - or "pipes" (Podolny, 2001) for the diffusion of influence, information and resources, differences in their internal "plumbing" ought to be associated with systematic individual differences among the nodes. What is less obvious is the active role that individual play in constructing their social infrastructure by changing "one-tieat-a-time." The model we have presented in this paper specifies how this process of change affects - and is affected by change in individual status. Elaborating on Podolny's powerful distinction (2001), networks are not only "pipes" through which resources and information flow, but also "prims" that change individual perceptions. In our study this is evident in our measure of status as a quality that is conferred by others, and on the basis of which perceptions are formed, change - and produce detectable social differences.

One possible way to frame the results of the study is in terms of social exchange. Individuals select advisors based on their status, and then advisors receive status for the advice they agree to provide (Blau, 1964; Lazega, Mounier, Snijders and Tubaro, 2011). Our findings suggest important qualifications to this view as exchange of status for advice may happen not only within, but also across networks - thus emphasizing the importance of the role played by network multiplexity (Snijders, Lomi and Torló, 2013). Consistently with the prediction of social exchange theory, student in our sample try to obtain advice from high-status alters possibly for instrumental reasons. However, what diffuses status are the expressive activities inherent in the friendship network, rather than the instrumental activities inherent in the advice network. Thus, the exchange of advice for status also happens across networks. High-status students see their status recognized in the advice network. But-high status student can also be more active in establishing the friendship ties through which status diffuses. This result opens the way for a more detailed examination of the role played by multiplexity- or how one effects produced by one network may operate and propagate through another (Torló, Lomi and Snijders, 2017).

A second way of framing our results is in terms of how status as the outcome of an aggregate social perception affects individual interpretations and meanings that individuals associate to network ties. This interpretation is supported by our representation of status as the consequence of attributions that may be influenced, but cannot be directly manipulated by individuals 
(Martin, 1998). From this angle, our main finding is that, over time, students come to perceive the status of their peers as similar to the perceived status of their network associates. Consequently, students collectively perceived as high status in one time period, may see their status decline in the next if their network associates are perceived to have lower status. This interpretation not only is consistent with Podolny's (2001: 58) view of networks as prisms "through which the qualities of actors are inferred (and, in our case, conferred) by potential exchange partners," but it also links it to the specific micro-level mechanisms of network change that we have identified.

The results we have reported suffer from a number of limitations. Three, in particular, deserve notice in this concluding section. The first limitation is linked to the specificity of the empirical setting that we have examined. While educational settings are useful because they reveal with clarity some of the relational aspects underlying processes of status construction in the absence of formal hierarchical distinctions, they also limit the scope of the results that might be obtained. Only attempts to replicate our results in different, and possibly more structured, organizational settings, can establish the extent to which our empirical results may be extended beyond the educational context that we have examined. It could well be than in more structured social settings (for example in formal organizations) the effect of positions occupied in a formal hierarchy will confound the deference relations that in our study we have observed among peers. In these settings, positions that individual occupy in the formal and informal hierarchies may become progressively decoupled - something that we do not observe in peer-groups like the one we examined in this paper.

The second limitation is directly related to our approach to representing and measuring social status. While we think that linking status to deference is aligned with current theoretical understanding of status as a relational asset resulting from endogenous social attributions, we relied on an aggregate measure that made it impossible to examine how individual acts of deference become interdependent over time and give rise to relatively enduring status hierarchies. Thus our current study shares with similar studies the limitations that are inherent in considering status an aggregate variable that may be treated as an attribute, rather than a process emerging from sequences of individual acts of deference possibly characterized by 
complex self-organizing properties. We think that this limitation provides a useful basis for future research into the mechanisms of status construction.

The third limitation of the study is the reconstruction of social status as something that individuals "receive" from others. As we have discussed, we think that the construct we have used is consistent with the most recent theoretical accounts of status as an "altercentric" rather than a "egocentric" social process. We acknowledge, however, that our approach is only partially consistent with a strict interpretation of SAOM as models for utility-maximizing individual decisions. In the paper, we alleviated this inconsistency by interpreting the estimates as probabilistic behavioral tendencies, rather than outcomes of a strict preferences ordering. In the context of our study, the utility-maximization framework of the model was interpreted as a heuristic device for representing decisions rather than as a normative statement about how decisions ought to be made by rational actors. We call on future research to provide models in which agency can be imputed to both senders as well as receivers, and may be represented as the outcome of a joint decision making process. This discussion suggests that caution is needed in the interpretation of the empirical results we have reported and in the evaluation of their scope conditions. Despite these various limitations, we believe our study illustrates a general analytical strategy that may be adopted to examine how social networks and social status coevolve in a broad variety of social situations that may be of interest. Attempts to replicate the results reported in this study and extend them to different settings, may produce a better understanding of how social networks and social status coevolve and shape one another over time and across multiple network domains. 


\title{
ABOUT THE AUTHORS
}

Vanina Jasmine Torlò works as Principal Lecturer in Strategic Management at the Department of Systems Management and Strategy of the Faculty of Business of the University of Greenwich. Her research brings social network theories into management to explain the existence of a feedback process linking network structures and outcomes in organisations. She has published several works on this subject in top-ranked international journals as well as book chapters in the field of strategy, organisational behaviour and social networks.

\begin{abstract}
Alessandro Lomi works at the Interdisciplinary Institute of Data Science of the University of Lugano, (Switzerland) where he also directs the Social Network Analysis Research (SONAR) Center. He is an honorary Senior Research Fellow at the School of Psychological Sciences of the University of Melbourne (Australia) and a life member of Clare Hall College, University of Cambridge (U.K). His interests include statistical models for social networks and the analysis of social relations within and between formal organizations.
\end{abstract}

\section{REFERENCES}

Agneessens, F. and Wittek, R. (2012). Where do intra-organizational advice relations come from? The role of informal status and social capital in social exchange, Social Networks, 34, 333-345.

Akerlof, G.A. and Kranton, R.E. (2002). Identity and Schooling: Some Lessons for the Economics of Education, Journal of Economic Literature, 40 (4), 1167-1201

Blau, P.M. (1964). Exchange and Power in Social Life. New York: Wiley.

Block, P., Stadtfeld, C. and Snijders, T.A., 2016. Forms of Dependence Comparing SAOMs and ERGMs From Basic Principles. Sociological Methods \& Research, IN press.

Bonacich P. and Lloyd, P. (2004). Calculating status with negative relations, Social Networks, 26, 331338.

Borgatti, S. P. and Foster, P. (2003). The network paradigm in organizational research: A review and typology, Journal of Management, 29(6), 991-1013.

Borgatti, S. P. and Halgin, D.S. (2011). On Network Theory, Organization Science, 22, 1157-1167.

Bothner, M., Podolny, J. and Smith, E. (2011). Organizing contests for status: The Matthew effect vs. the Mark effect, Organization Science, 57, 439-457.

Bothner, M.S., Stuart, T.E. and White, H.C. (2004). Status differentiation and the cohesion of social networks. Journal of Mathematical Sociology, 28, 261-295.

Bothner, M.S. Haynes, R., Lee, W. and Smith, E. (2010). When Do Matthew Effects Occur? Journal of Mathematical Sociology, 34, 80-114.

Bothner, M.S., Godart, F.C., and Lee W. (2014). What is social status? Comparisons and contrasts with cognate concepts. Industrial and corporate change, Forthcoming. 
Brass, D.J., Galaskiewicz, J., Greve, H.R. and Tsai, W. (2004. Taking stock of networks and organizations: A multilevel perspective, Academy of Management Journal, 47(6), 795- 817.

Breiger, R.L. (2000). A toolkit for practice theory. Poetics, 27, 91-115.

Burt, R. (2013). Embedded brokerage. In S.P. Borgatti, D.J. Brass, D.S. Halgin, G. Labianca, and A. Mehra (Eds.). Contemporary Perspectives on Organizational Social Network Analysis. Research in the Sociology of Organizations. Emerald Press (Forthcoming).

Chan, T.W. and Goldthorpe, J.H. (2007). Social Status and Newspaper Readership, American Journal of Sociology, 112(4), 1095-1134.

Chase, I. D. (1982). Behavioral Sequences During Dominance Hierarchy Formation in Chickens, Science, 216, 439-440.

Chen, Y., Peterson, R., Phillips, D., Podolny, J., and Ridgeway, C. (2012) (in press). Bringing "status" to the table: Attaining, maintaining, and experiencing status in organizations and markets. Organization Science.

Chung, S. A., Singh, H. and Lee, K. (2000). Complementarity, status similarity and social capital as drivers of alliance formation, Strategic Management Journal, 21(1), 1-22.

Coleman, J.S., Campbell, E.Q., Hobson, C.J., McPartland, F., Mood, A.M., Weinfeld, F.D., et al, (1966). Equality of Educational Opportunity. Government Printing Office, Washington, DC.

Connie, Y.Y., Gay, G. (2006). Homophily of Network Ties and Bonding and Bridging Social Capital in Computer-Mediated Distributed Teams. Journal of Computer Mediated Communication, 11(4), 1062-1084.

Cross, R., Borgatti, S.P. and Parker, A. (2001). Beyond answers: dimensions of the advice network, Social Networks, 23 (3), 215-235. Faris

Di Maggio, P., and Garip F. (2012). Network effects and Social Inequality, Annual Review of Sociology, 38, 93-118.

Gould, R. (2002). The origins of status hierarchies: a formal theory and empirical test, American Journal of Sociology, 107, 1143-1178.

Granovetter, M. (1974). Getti Faris Faris ng a Job: A Study of Contacts and Careers. Harvard University Press, Cambridge, Mass.

Faris, R. and Felmlee, D., 2011. Status Struggles: Network Centrality and Gender Segregation in Same- and Cross-Gender Aggression. American Sociological Review, Vol. 76, No. 1: pp. 4873.

Fiske, S. T. (2010). Interpersonal stratification: Status, power, and subordination. In S. T. Fiske, G. Lindzey, \& D. T. Gilbert (Eds.) Handbook of social psychology (5th ed., pp. 941-982). Hoboken, NJ: Wiley.

Hintze, J. L. and R. D. Nelson. (1998). Violin Plots: A Box Plot-Density Trace Synergism. The American Statistician 52:181-84.

Kilduff, M. (1990). The Interpersonal structure of decision making: a social comparison approach to organizational choice, Organizational Behavior and Human Decision Processes, 47(2), 270288.

Kilduff, M. (1992). The friendship network as a decision making resource: dispositional moderators of social influences on organizational choice, Journal of Personality and Social Psychology, 62 (1), 168-180. 
Kilduff, M. and Krackhardt, D. (1994). Bringing the individual back in: A structural analysis of the internal market for reputation in organizations. Academy of Management Journal, 37(1), 87108.

Kilduff, M., Krackhardt, D., (2008). Interpersonal Networks in Organizations: Cognition, Personality, Dynamics, and Culture. Cambridge University Press, New York, NY.

Lazega, E., Mounier, L., Snijders, T.A.B. and Tubaro, P. (2011). Norms, status and the dynamics of advice networks: A case study, Social Networks, 34 (3), 323-332.

Lazarsfeld PF, Merton RK. (1954). Friendship as a social process: a substantive and methodological analysis. In Freedom and Control in Modern Society, ed. M Berger, pp. 18-66. New York: Van Nostrand

Lewis, K., Gonzalez, M., and Kaufman J. (2012). Social selection and peer influence in an online social network, PNAS, vol. 109(1), 68-72.

Lynn, F.B., Podolny, J.M. and Tao, L. (2009). A sociological (de)construction of the relationship between status and quality, American Journal of Sociology, 115, 755-804.

Lomi, A., Snijders, T.A.B., Steglich, C.E.G. and Torlò, V.J. (2011). Why are some more peer than others? Evidence from a longitudinal study of social networks and individual academic performance, Social Science Research, 40, 1506-1520.

Lospinoso, J. A. (2012). Statistical Models for Social Network Dynamics. PhD thesis, University of Oxford, U.K.

Magee, J. C., and Galinsky, A. D. 2008. Social hierarchy: The self-reinforcing nature of power and status, Academy of Management Annals, 2(1), 351-398.

Martin, J.L., 1998. Structures of power in naturally occurring communities. Social networks, 20(3), pp.197-225.

McPherson, J.M., and Smith-Lovin, L. (1987). Homophily in Voluntary Organizations: Status Distance and the Composition of Face-to-Face Groups, American Sociological Review, 52, 3370-379.

McPherson, M., Smith-Lovin, L., and Cook, J.M. (2001). Birds of a Feather: homophily in social networks, Annual Review of Sociology, 27, 415-444.

Noah P. Mark, N. Lynn Smith-Lovin, L. and Ridgeway, C.L. (2009). Why Do Nominal Characteristics Acquire Status Value? A Minimal Explanation for Status Construction, American Journal of Sociology, 115(3), 832-862.

Ollivier M., (2004). Towards a structural theory of status inequality. In Research in Social Stratification and Mobility, ed. AL Kalleberg, SL Morgan, J Myles, RA Rosenfeld, pp. 187-213. Oxford: Elsevier.

Pachucki, M. A. and Breiger, R. L. (2010). Cultural holes: Beyond relationality in social networks and culture, Annual Review of Sociology, 36, 205-224.

Phillips, D. and Zuckerman, E. (2001). Middle-status conformity: Theoretical restatement and empirical demonstration in two markets, American Journal of Sociology, 107, 379-429.

Podolny, J.M. (1993). A status-based model of market competition, American Journal of Sociology, 984, 829-72

Podolny, J.M. (2001). Networks as the pipes and prisms of the market, American Journal of Sociology, 1071, 33-60.

Podolny, J.M. and Phillips, D.J. (1996). The dynamics of social status, Industrial and Corporate 
Change, 5 (2), 453-471.

Podolny JM. (2005). Status Signals: A Sociological Study of Market Competition. Princeton, NJ: Princeton Univ. Press

Ridgeway, C.L. (1984). Dominance, performance, and status in groups, Advances in Group Process, 1, 59-93.

Ripley, R.M. Snijders, T.A.B, Boda, Z., Voros, A., Preciado, P. (2016). Manual for RSienalUniversity of Oxford, Department of Statistics; Nuffield College.

Rossman, G., Esparza, N. and Bonacich, P. (2010). I'd Like to Thank the Academy, Team Spillovers, and Network Centrality, American Sociological Review, 75(1), 31-51.

Salganik, M.J., Dodds, P.S., and Watts, D.J. (2006). Experimental Study of Inequality and Unpredictability in an Artificial Cultural Market, Science, 311(5762), 854-856

Sampson, S.P. (1968). A Novitiate in a Period of Change: An Experimental and Case Study of Social Relationships. Dissertation, Cornell University.

Sauder, M., Lynn, F. and Podolny, J.M. (2012). Status: Insights from Organizational Sociology, The Annual Review of Sociology, 38, 14.1-14.17.

Simmel, G., 1971 (1908). The Stranger. In Georg Simmel: On Individuality and Social Forms, edited by Donald N. Levine, 143-50. Chicago: Univ. of Chicago Press.

Smith, E. B., Menon, T., and Thompson, L. (2012). Status differences in the cognitive activation of social networks, Organization Science, 23, 67-82.

Snijders, T. A. (2017). Stochastic actor-oriented models for network dynamics. Annual Review of Statistics and Its Application, (In Press).

Snijders, T.A.B. (2005). Models for longitudinal network data. In: Carrington, P.J., Scott,J., Wasserman, S. (Eds.), Models and Methods in Social Network Analysis. Cambridge University Press, New York, pp. 215-247.

Snijders, T.A.B., (2001). The statistical evaluation of social network dynamics. In: Sobel, M., Becker, M. (Eds.), Sociological Methodology. Basil Blackwell, Boston and London, pp. 361-395.

Snijders, T.A.B., Lomi, A., and Torló, V.J. (2013). A Model for the Multiplex Dynamics of Two-mode and One-mode Networks, with an Application to Employment Preferences, Friendship and Advice, Social Networks, 35(2), 265-276.

Snijders, T.A.B., and Steglich, C.E.G. (2015). Representing Micro-Macro Linkages by Actor-based Dynamic Network Models Sociological Methods \& Research Vol. 44(2) 222-271.

Snijders, T.A.B., Steglich, C.E.G. and Schweinberger, M. (2007). Modeling the co-evolution of networks and behavior. In: van Montfort, K., Oud, H., Satorra, A. (Eds.), Longitudinal Models in the Behavioral and Related Sciences. Lawrence Erlbaum, Mahwah, NJ, pp. 41-71.

Snijders, T.A.B., van de Bunt, G.G. and Steglich, C.E.G. (2010). Introduction to actor-based models for Network Dynamics, Social Networks, 32, 44-60.

Steglich, C.E.G., Snijders, T.A.B. and Pearson, M. (2010). Dynamic network and behavior: separating selection from influence, Sociological Methodology, 40, 329-392.

Steglich, C., Snijders, T.A. and West, P., 2006. Applying Siena. Methodology, 2(1), pp.48-56

Thye, S. R. (2000). A status value theory of power in exchange relations, American Sociological Review, 65(3), 407-432. 
Torló, Lomi and Snijders, 2017. No network comes alone: the dynamics of multiplexity. In Tom A.B. Snijders and Christian E.G. Steglich, editors. Social Network Dynamics by Examples. Structural Analysis in the Social Sciences. New York: Cambridge University Press, Forthcoming.

White, H.C., (1992). Identity and control: A structural theory of social action. Princeton University Press. 


\section{Figure legend}

Figure 1a - Evolution of the friendship network over time

Figure 1b - Evolution of the advice network over time

Figure 2a: Indegree distribution (p: 0.552)

Figure 2b: Outdegree distribution (p: 0.414)

Figure 2a and 2b. Diagnostic goodness of fit plots of the observed data (red line) against data simulated on the basis of the empirical estimates (number of simulations $\mathrm{s}=1000$ ). Dashed grey lines represent the 90 interval of the estimated distribution of networks. The p-values associated with the Mahalanobis distance test are reported under each figure.

Figure 3. Diagnostic goodness of fit plots of the observed (cumulated) status variable (red line) against data simulated on the basis of the empirical estimates (number of simulations s $=1000$ ). Dashed grey lines represent the 90 interval of the estimated distribution of networks. 
Table 1- Attribute variables: descriptive statistics, $N=75$

(Standard deviations in parentheses)

\begin{tabular}{|l|c|c|c|c|c|c|}
\hline Variables & Type & $\begin{array}{c}\text { Units of } \\
\text { Measure }\end{array}$ & $\begin{array}{c}\text { Sample } \\
\text { Statistic }\end{array}$ & S.D. & Min & Max \\
\hline Business administration background & Monadic & Category & $50 \%$ & $/$ & 1 & 6 \\
\hline $\begin{array}{l}\text { Percentage of foreign students (non- } \\
\text { Italian) }\end{array}$ & Monadic & Indicator & $13 \%$ & $/$ & 1 & 2 \\
\hline Proportion of males & Monadic & Indicator & $62 \%$ & $/$ & 1 & 2 \\
\hline Average Age & Monadic & Years & 29 & 3 & 24 & 40 \\
\hline Work experience & Monadic & Months & 19 & 27 & 0 & 168 \\
\hline GPA (Ability) & Monadic & Units & 105.51 & 4.71 & 93 & 111 \\
\hline Performance & Monadic & Units & 25.99 & 1.59 & 20 & 30 \\
\hline
\end{tabular}


Table 2- Descriptive network statistics

\begin{tabular}{|c|c|c|c|c|c|c|c|}
\hline $\begin{array}{l}\text { Network } \\
\text { Statistics }\end{array}$ & Definition & $\begin{array}{l}\text { Friendship } \\
\quad \text { T1 }\end{array}$ & $\begin{array}{l}\text { Friendship } \\
\quad \text { T2 }\end{array}$ & $\begin{array}{l}\text { Friendship } \\
\text { T3 }\end{array}$ & $\begin{array}{l}\text { Advice } \\
\text { T1 }\end{array}$ & $\begin{array}{l}\text { Advice } \\
\text { T2 }\end{array}$ & $\begin{array}{c}\text { Advice } \\
\text { T3 }\end{array}$ \\
\hline $\begin{array}{c}\text { Average } \\
\text { degree } \\
\text { (s.d. } \\
\text { in/out) }\end{array}$ & $\begin{array}{l}\text { Average number of edges } \\
\text { incident with nodes }\end{array}$ & $\begin{array}{c}9.9 \\
(9.5 / 6.2)\end{array}$ & $\begin{array}{c}9.2 \\
(9.3 / 5.5)\end{array}$ & $\begin{array}{c}8.3 \\
(6.8 / 5.3)\end{array}$ & $\begin{array}{c}4.1 \\
(2.5 / 5.6)\end{array}$ & $\begin{array}{c}4.9 \\
(3.1 / 5.5)\end{array}$ & $\begin{array}{c}4.5 \\
(3.2 / 5.7)\end{array}$ \\
\hline Reciprocity & Proportion of reciprocated ties & 0.58 & 0.54 & 0.57 & 0.29 & 0.33 & 0.33 \\
\hline Clustering & $\begin{array}{l}\text { Average density of the open } \\
\text { neigbborbood around each node }\end{array}$ & 0.44 & 0.40 & 0.38 & 0.24 & 0.24 & 0.26 \\
\hline
\end{tabular}


Table 3. Change statistics for network ties over time: friendship and advice networks

\begin{tabular}{|l|c|c|c|c|c|c|}
\hline \multicolumn{1}{|c|}{$\mathrm{t}_{\mathrm{k}} \rightarrow \mathrm{t}_{\mathrm{k}+1}$} & $0 \rightarrow 0$ & $0 \rightarrow 1$ & $1 \rightarrow 0$ & $1 \rightarrow 1$ & Distance & Missing \\
\hline Friendship & & & & & & \\
\hline $1 \rightarrow 2$ & 4578 & 231 & 280 & 461 & 511 & 0 \\
\hline $2 \rightarrow 3$ & 4705 & 153 & 226 & 466 & 379 & 0 \\
\hline \multicolumn{7}{|l|}{} \\
\hline Advice & 5060 & 183 & 123 & 184 & 306 & 0 \\
\hline $1 \rightarrow 2$ & 5058 & 125 & 151 & 216 & 276 & 0 \\
\hline $2 \rightarrow 3$
\end{tabular}


Table 4 - Network effects included in the objective functions. Interpretation of the effects is exemplified in the context of advice relations.

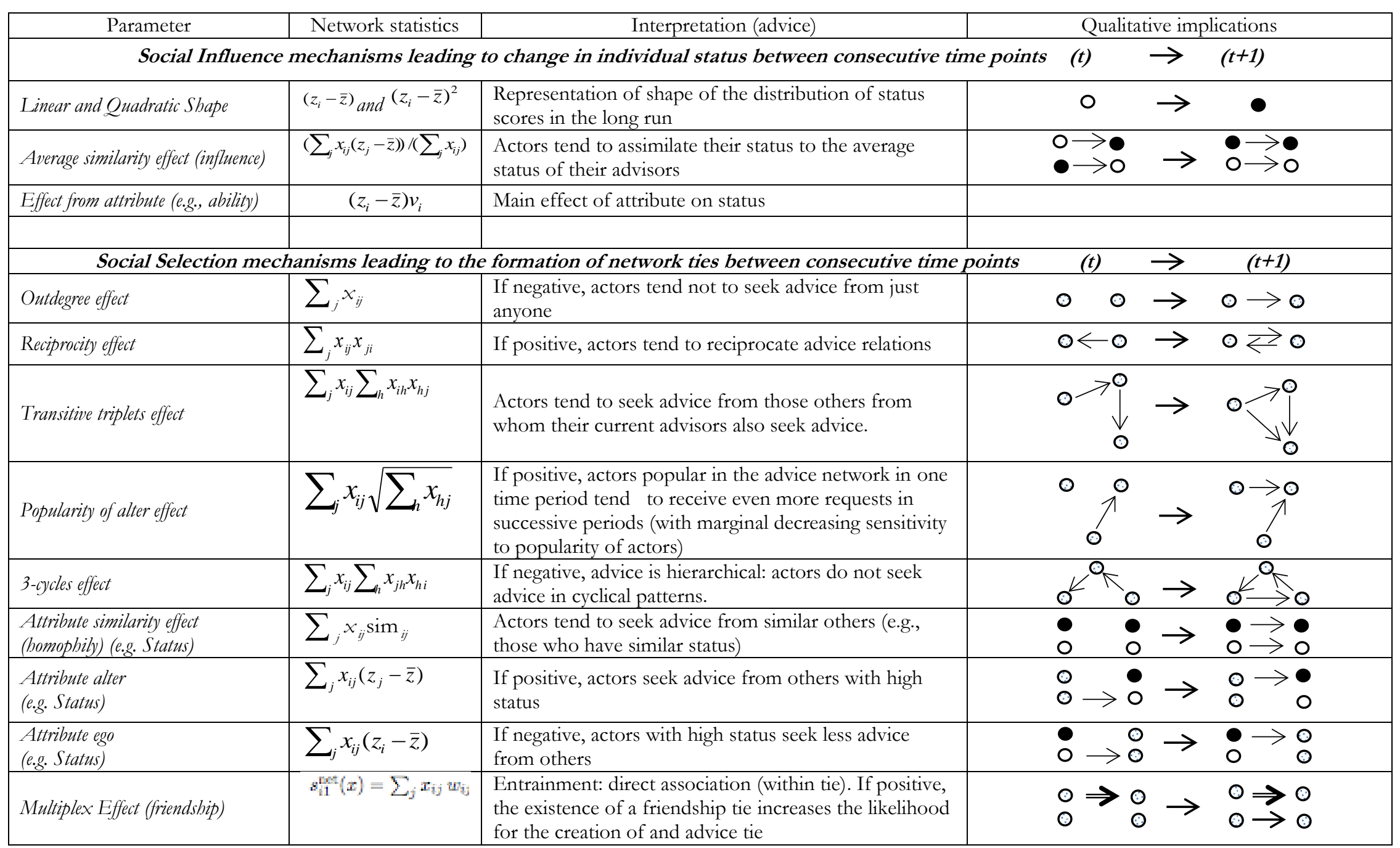


Dotted nodes represent students irrespective of their values for attributes. White (black) nodes represent students with low (high) value of attributes. Single arrow represents advice ties; Double arrow represents friendship ties. 
Table 5 - QAP correlations between advice, deference and friendship relations ${ }^{5}$

\begin{tabular}{|c|c|c|c|c|c|c|c|c|c|}
\hline & $\begin{array}{c}\text { Advice } \\
\text { T1 }\end{array}$ & $\begin{array}{c}\text { Advice } \\
\text { T2 }\end{array}$ & $\begin{array}{c}\text { Advice } \\
\text { T3 }\end{array}$ & $\begin{array}{c}\text { Deference } \\
\text { T1 }\end{array}$ & $\begin{array}{c}\text { Deference } \\
\text { T2 }\end{array}$ & $\begin{array}{c}\text { Deference } \\
\text { T3 }\end{array}$ & $\begin{array}{c}\text { Friendship } \\
\text { T1 }\end{array}$ & $\begin{array}{c}\text { Friendship } \\
\text { T2 }\end{array}$ & $\begin{array}{c}\text { Friendship } \\
\text { T3 }\end{array}$ \\
\hline Advice T2 & 0.519 & 1.000 & 0.584 & 0.370 & 0.496 & 0.389 & 0.262 & 0.363 & 0.348 \\
\hline Advice T3 & 0.506 & 0.584 & 1.000 & 0.367 & 0.452 & 0.481 & 0.264 & 0.326 & 0.350 \\
\hline Deference T2 & 0.368 & 0.496 & 0.452 & 0.555 & 1.000 & 0.576 & 0.210 & 0.314 & 0.301 \\
\hline Deference T3 & 0.324 & 0.389 & 0.481 & 0.507 & 0.576 & 1.000 & 0.186 & 0.252 & 0.273 \\
\hline Friendship T1 & 0.276 & 0.262 & 0.264 & 0.240 & 0.210 & 0.186 & 1.000 & 0.591 & 0.527 \\
\hline
\end{tabular}

5 All the correlation coefficients are significant at the level $\mathrm{p}<0.01$ 
Table 6a. Determinants of individual status (standard errors in parentheses).

\begin{tabular}{|c|c|c|c|c|c|c|c|c|c|}
\hline EFFECTS & $\begin{array}{l}\text { Friendship } \\
\text { (Null) }\end{array}$ & $\begin{array}{l}\text { Friendship } \\
\text { (Restricted 1) }\end{array}$ & $\begin{array}{l}\text { Friendship } \\
\text { ( Restricted 2) }\end{array}$ & $\begin{array}{l}\text { Friendship } \\
\text { (Full) }\end{array}$ & $\begin{array}{l}\text { Advice } \\
\text { (Null) }\end{array}$ & $\begin{array}{c}\text { Advice } \\
\text { (Restricted 1) }\end{array}$ & $\begin{array}{c}\text { Advice } \\
\text { (Restricted 2) }\end{array}$ & $\begin{array}{l}\text { Advice } \\
\text { (Full) }\end{array}$ & $\begin{array}{c}\text { Multiplex } \\
\text { Analysis } \\
(\mathrm{F}+\mathrm{A})\end{array}$ \\
\hline Rate Period 1-2 & $\begin{array}{c}16.327 * \\
(3.430)\end{array}$ & $\begin{array}{c}18.080 * \\
(4.438)\end{array}$ & $\begin{array}{c}18.112 * \\
(4.588)\end{array}$ & $\begin{array}{c}18.119 * \\
(3.258) \\
\end{array}$ & $\begin{array}{c}16.339 * \\
(3.433) \\
\end{array}$ & $\begin{array}{c}16.052 * \\
(5.507) \\
\end{array}$ & $\begin{array}{c}16.210 * \\
(4.161)\end{array}$ & $\begin{array}{c}16.094 * \\
(2.899) \\
\end{array}$ & $\begin{array}{l}16.914^{*} \\
(8.488)\end{array}$ \\
\hline Rate Period 2-3 & $\begin{array}{c}14.632 * \\
(4.257) \\
\end{array}$ & $\begin{array}{c}16.388 * \\
(3.018) \\
\end{array}$ & $\begin{array}{c}16.301 * \\
(3.486) \\
\end{array}$ & $\begin{array}{c}16.269 * \\
(3.453) \\
\end{array}$ & $\begin{array}{c}14.676^{*} \\
(3.072) \\
\end{array}$ & $\begin{array}{c}14.687 * \\
(3.930) \\
\end{array}$ & $\begin{array}{c}14.898^{*} \\
(6.043) \\
\end{array}$ & $\begin{array}{c}14.876 * \\
(3.063) \\
\end{array}$ & $\begin{array}{c}15.004+ \\
(7.910) \\
\end{array}$ \\
\hline Linear Shape & $\begin{array}{c}0.053 \\
(0.039)\end{array}$ & $\begin{array}{c}0.034 \\
(0.042)\end{array}$ & $\begin{array}{c}0.037 \\
(0.037)\end{array}$ & $\begin{array}{c}0.035 \\
(0.038)\end{array}$ & $\begin{array}{c}0.054 \\
(0.043)\end{array}$ & $\begin{array}{c}0.099 \\
(0.133)\end{array}$ & $\begin{array}{c}0.101 \\
(0.301)\end{array}$ & $\begin{array}{c}0.105 \\
(0.098) \\
\end{array}$ & $\begin{array}{c}0.050 \\
(0.051)\end{array}$ \\
\hline Quadratic Shape & $\begin{array}{l}-0.003 \\
(0.003) \\
\end{array}$ & $\begin{array}{l}-0.003 \\
(0.004) \\
\end{array}$ & $\begin{array}{l}-0.003 \\
(0.004) \\
\end{array}$ & $\begin{array}{l}-0.003 \\
(0.004) \\
\end{array}$ & $\begin{array}{l}-0.003 \\
(0.002) \\
\end{array}$ & $\begin{array}{l}-0.013 \\
(0.012) \\
\end{array}$ & $\begin{array}{l}-0.013 \\
(0.028) \\
\end{array}$ & $\begin{array}{l}-0.013 \\
(0.008) \\
\end{array}$ & $\begin{array}{c}0.000 \\
(0.003)\end{array}$ \\
\hline Average similarity & - & $\begin{array}{c}5.904 \\
(4.692) \\
\end{array}$ & $\begin{array}{c}5.931 \\
(4.155) \\
\end{array}$ & $\begin{array}{l}5.834^{*} \\
(2.984) \\
\end{array}$ & - & $\begin{array}{c}-7.217 \\
(14.514) \\
\end{array}$ & $\begin{array}{c}-6.965 \\
(16.815) \\
\end{array}$ & $\begin{array}{l}-7.355 \\
(9.922) \\
\end{array}$ & - \\
\hline $\begin{array}{l}\text { Average similarity } \\
\text { (Friendship) }\end{array}$ & - & - & - & - & - & - & - & - & $\begin{array}{l}5.004^{*} \\
(2.575)\end{array}$ \\
\hline Ability & - & $\begin{array}{c}0.002 \\
(0.008)\end{array}$ & $\begin{array}{c}0.002 \\
(0.009)\end{array}$ & $\begin{array}{c}0.002 \\
(0.008)\end{array}$ & - & $\begin{array}{c}0.004 \\
(0.009)\end{array}$ & $\begin{array}{c}0.004 \\
(0.009)\end{array}$ & $\begin{array}{c}0.004 \\
(0.009)\end{array}$ & $\begin{array}{c}0.007 \\
(0.007)\end{array}$ \\
\hline
\end{tabular}

$* \mathrm{p}<0.05$. 
Table 6b.Determinants of network ties (standard errors in parentheses).

\begin{tabular}{|c|c|c|c|c|c|c|c|c|c|c|c|}
\hline & & EFFECTS & $\begin{array}{l}\text { Friendship } \\
\text { (Null) }\end{array}$ & $\begin{array}{l}\text { Friendship } \\
\text { (Restricted 1) }\end{array}$ & $\begin{array}{l}\text { Friendship } \\
\text { (Restricted 2) }\end{array}$ & $\begin{array}{l}\text { Friendship } \\
\quad \text { (Full) }\end{array}$ & $\begin{array}{l}\text { Advice } \\
\text { (Null) }\end{array}$ & $\begin{array}{c}\text { Advice } \\
\text { (Restricted 1) }\end{array}$ & $\begin{array}{c}\text { Advice } \\
\text { (Restricted2) }\end{array}$ & $\begin{array}{l}\text { Advice } \\
\text { (Full) }\end{array}$ & $\begin{array}{c}\text { Multiplex } \\
\text { Analysis } \\
(\mathrm{F}+\mathrm{A})\end{array}$ \\
\hline \multirow{13}{*}{ 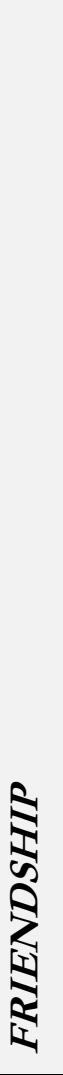 } & & Rate Period 1-2 & $\begin{array}{l}7.641 * \\
(0.359) \\
\end{array}$ & $\begin{array}{c}15.704 * \\
(1.111) \\
\end{array}$ & $\begin{array}{c}15.853 * \\
(0.996) \\
\end{array}$ & $\begin{array}{c}15.688 * \\
(1.071)\end{array}$ & - & - & - & - & $\begin{array}{c}15.743^{* * *} \\
(1.929)\end{array}$ \\
\hline & & Rate Period 2-3 & $\begin{array}{l}5.527 * \\
(0.306)\end{array}$ & $\begin{array}{l}8.722 * \\
(0.615)\end{array}$ & $\begin{array}{l}8.850 * \\
(0.594)\end{array}$ & $\begin{array}{l}8.756^{*} \\
(0.628)\end{array}$ & - & - & - & - & $\begin{array}{l}9.348^{* * *} \\
(0.963)\end{array}$ \\
\hline & \multirow{5}{*}{ 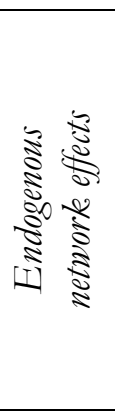 } & Outdegree (density) & - & $\begin{array}{l}-1.868^{*} \\
(0.128)\end{array}$ & $\begin{array}{l}-2.639 * \\
(0.258)\end{array}$ & $\begin{array}{l}-2.532^{*} \\
(0.261)\end{array}$ & - & - & - & - & $\begin{array}{l}-2.503^{* * *} \\
(0.167)\end{array}$ \\
\hline & & Reciprocity & - & $\begin{array}{l}1.501^{*} \\
(0.108)\end{array}$ & $\begin{array}{l}1.414^{*} \\
(0.087)\end{array}$ & $\begin{array}{l}1.417^{*} \\
(0.090)\end{array}$ & - & - & - & - & $\begin{array}{l}1.404^{* * *} \\
(0.122)\end{array}$ \\
\hline & & Transitive triplets & - & $\begin{array}{l}0.139^{*} \\
(0.008) \\
\end{array}$ & $\begin{array}{l}0.146^{*} \\
(0.009) \\
\end{array}$ & $\begin{array}{l}0.146^{*} \\
(0.009)\end{array}$ & - & - & - & - & $\begin{array}{l}0.195^{* * *} \\
(0.017)\end{array}$ \\
\hline & & $\begin{array}{l}\text { Popularity of alter } \\
\text { (sqrt measure) }\end{array}$ & - & $\begin{array}{l}-0.087^{*} \\
(0.042)\end{array}$ & $\begin{array}{l}-0.133^{*} \\
(0.046)\end{array}$ & $\begin{array}{l}-0.133^{*} \\
(0.047)\end{array}$ & - & - & - & - & $\begin{array}{c}0.060 \\
(0.061)\end{array}$ \\
\hline & & 3-cycles & - & $\begin{array}{l}-0.209^{*} \\
(0.021)\end{array}$ & $\begin{array}{l}-0.196^{*} \\
(0.023)\end{array}$ & $\begin{array}{l}-0.196^{*} \\
(0.023)\end{array}$ & - & - & - & - & $\begin{array}{l}-0.169^{* * *} \\
(0.028)\end{array}$ \\
\hline & \multirow{6}{*}{  } & Gender (M) alter & - & - & $\begin{array}{l}-0.174 \\
(0.117)\end{array}$ & $\begin{array}{l}-0.159 \\
(0.113)\end{array}$ & - & - & - & - & $\begin{array}{c}0.082 \\
(0.105)\end{array}$ \\
\hline & & Gender (M) ego & - & - & $\begin{array}{c}0.064 \\
(0.086)\end{array}$ & $\begin{array}{c}0.063 \\
(0.086)\end{array}$ & - & - & - & - & $\begin{array}{l}-0.120 \\
(0.102)\end{array}$ \\
\hline & & Gender (M) similarity & - & - & $\begin{array}{l}0.421^{*} \\
(0.143)\end{array}$ & $\begin{array}{l}0.403^{*} \\
(0.136)\end{array}$ & - & - & - & - & $\begin{array}{l}0.225^{* *} \\
(0.073) \\
\end{array}$ \\
\hline & & Ability alter & - & - & $\begin{array}{l}-0.002 \\
(0.007)\end{array}$ & $\begin{array}{l}-0.002 \\
(0.007)\end{array}$ & - & - & - & - & $\begin{array}{l}-0.005 \\
(0.011)\end{array}$ \\
\hline & & Ability ego & - & - & $\begin{array}{c}0.009 \\
(0.007)\end{array}$ & $\begin{array}{c}0.012 \\
(0.007)\end{array}$ & - & - & - & - & $\begin{array}{c}0.009 \\
(0.008)\end{array}$ \\
\hline & & Ability similarity & - & - & $\begin{array}{l}-0.060 \\
(0.147)\end{array}$ & $\begin{array}{l}-0.104 \\
(0.147)\end{array}$ & - & - & - & - & $\begin{array}{l}-0.151 \\
(0.229)\end{array}$ \\
\hline
\end{tabular}




\begin{tabular}{|c|c|c|c|c|c|c|c|c|c|c|}
\hline & Age alter & - & - & $\begin{array}{c}0.009 \\
(0.013) \\
\end{array}$ & $\begin{array}{c}0.010 \\
(0.012) \\
\end{array}$ & - & - & - & - & $\begin{array}{c}0.020 \\
(0.013) \\
\end{array}$ \\
\hline & Age ego & & & $\begin{array}{c}0.021 \\
(0.012) \\
\end{array}$ & $\begin{array}{c}0.016 \\
(0.012)\end{array}$ & & & - & - & $\begin{array}{c}0.013 \\
(0.013)\end{array}$ \\
\hline & Age similarity & - & - & $\begin{array}{c}0.406 \\
(0.214)\end{array}$ & $\begin{array}{l}0.417^{*} \\
(0.206)\end{array}$ & - & - & - & - & $\begin{array}{c}0.481+ \\
(0.249)\end{array}$ \\
\hline & Academic background alter & - & - & $\begin{array}{l}-0.029 \\
(0.031) \\
\end{array}$ & $\begin{array}{l}-0.030 \\
(0.029) \\
\end{array}$ & - & - & - & - & $\begin{array}{l}-0.033 \\
(0.034) \\
\end{array}$ \\
\hline & Academic background ego & - & - & $\begin{array}{l}-0.082^{*} \\
(0.032) \\
\end{array}$ & $\begin{array}{l}-0.090^{*} \\
(0.033) \\
\end{array}$ & - & - & - & - & $\begin{array}{c}-0.090^{*} \\
(0.034)\end{array}$ \\
\hline & Academic background similarity & - & - & $\begin{array}{l}-0.072 \\
(0.152)\end{array}$ & $\begin{array}{l}-0.096 \\
(0.162)\end{array}$ & - & - & - & - & $\begin{array}{l}-0.162 \\
(0.211)\end{array}$ \\
\hline & Work experience alter & - & - & $\begin{array}{l}-0.044 \\
(0.077)\end{array}$ & $\begin{array}{l}-0.049 \\
(0.074)\end{array}$ & - & - & - & - & $\begin{array}{l}-0.060 \\
(0.098) \\
\end{array}$ \\
\hline & Work experience ego & - & - & $\begin{array}{l}-0.013 \\
(0.072) \\
\end{array}$ & $\begin{array}{l}-0.069 \\
(0.074) \\
\end{array}$ & - & - & - & - & $\begin{array}{l}-0.046 \\
(0.076) \\
\end{array}$ \\
\hline & Work experience similarity & - & - & $\begin{array}{c}0.042 \\
(0.060) \\
\end{array}$ & $\begin{array}{c}0.041 \\
(0.063) \\
\end{array}$ & - & - & - & - & $\begin{array}{c}0.005 \\
(0.069) \\
\end{array}$ \\
\hline & Nationality alter & - & - & $\begin{array}{c}-0.033^{*} \\
(0.118)\end{array}$ & $\begin{array}{l}-0.012 \\
(0.118)\end{array}$ & - & - & - & - & $\begin{array}{l}0.347^{*} \\
(0.139)\end{array}$ \\
\hline & Nationality ego & - & - & $\begin{array}{l}0.505^{*} \\
(0.207)\end{array}$ & $\begin{array}{l}0.430^{*} \\
(0.200)\end{array}$ & - & - & - & - & $\begin{array}{l}0.285^{*} \\
(0.127)\end{array}$ \\
\hline & Nationality similarity & - & - & $\begin{array}{l}0.577^{*} \\
(0.243) \\
\end{array}$ & $\begin{array}{l}0.461^{*} \\
(0.221) \\
\end{array}$ & - & - & - & - & $\begin{array}{c}0.419^{* *} \\
(0.119)\end{array}$ \\
\hline & Performance alter & - & - & $\begin{array}{l}-0.007 \\
(0.026)\end{array}$ & $\begin{array}{l}-0.015 \\
(0.030)\end{array}$ & - & - & - & - & $\begin{array}{l}-0.046 \\
(0.036)\end{array}$ \\
\hline & Performance ego & - & - & $\begin{array}{l}-0.069^{*} \\
(0.029)\end{array}$ & $\begin{array}{l}-0.132 * \\
(0.032)\end{array}$ & - & - & - & - & $\begin{array}{c}-0.119^{* *} \\
(0.032)\end{array}$ \\
\hline & Performance similarity & - & - & $\begin{array}{l}0.836^{*} \\
(0.193)\end{array}$ & $\begin{array}{l}0.996^{*} \\
(0.205)\end{array}$ & - & - & - & - & $\begin{array}{l}1.029 \text { *** } \\
(0.211)\end{array}$ \\
\hline \multirow{3}{*}{ 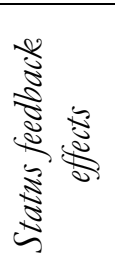 } & Status alter & - & - & - & $\begin{array}{c}0.005 \\
(0.009) \\
\end{array}$ & - & - & - & - & $\begin{array}{r}0.005 \\
(0.009) \\
\end{array}$ \\
\hline & Status ego & - & - & - & $\begin{array}{l}0.026^{*} \\
(0.009)\end{array}$ & - & - & - & - & $\begin{array}{l}0.026^{*} \\
(0.011)\end{array}$ \\
\hline & Status similarity & - & - & - & $\begin{array}{c}0.157 \\
(0.388)\end{array}$ & - & - & - & - & $\begin{array}{c}0.083 \\
(0.452)\end{array}$ \\
\hline
\end{tabular}




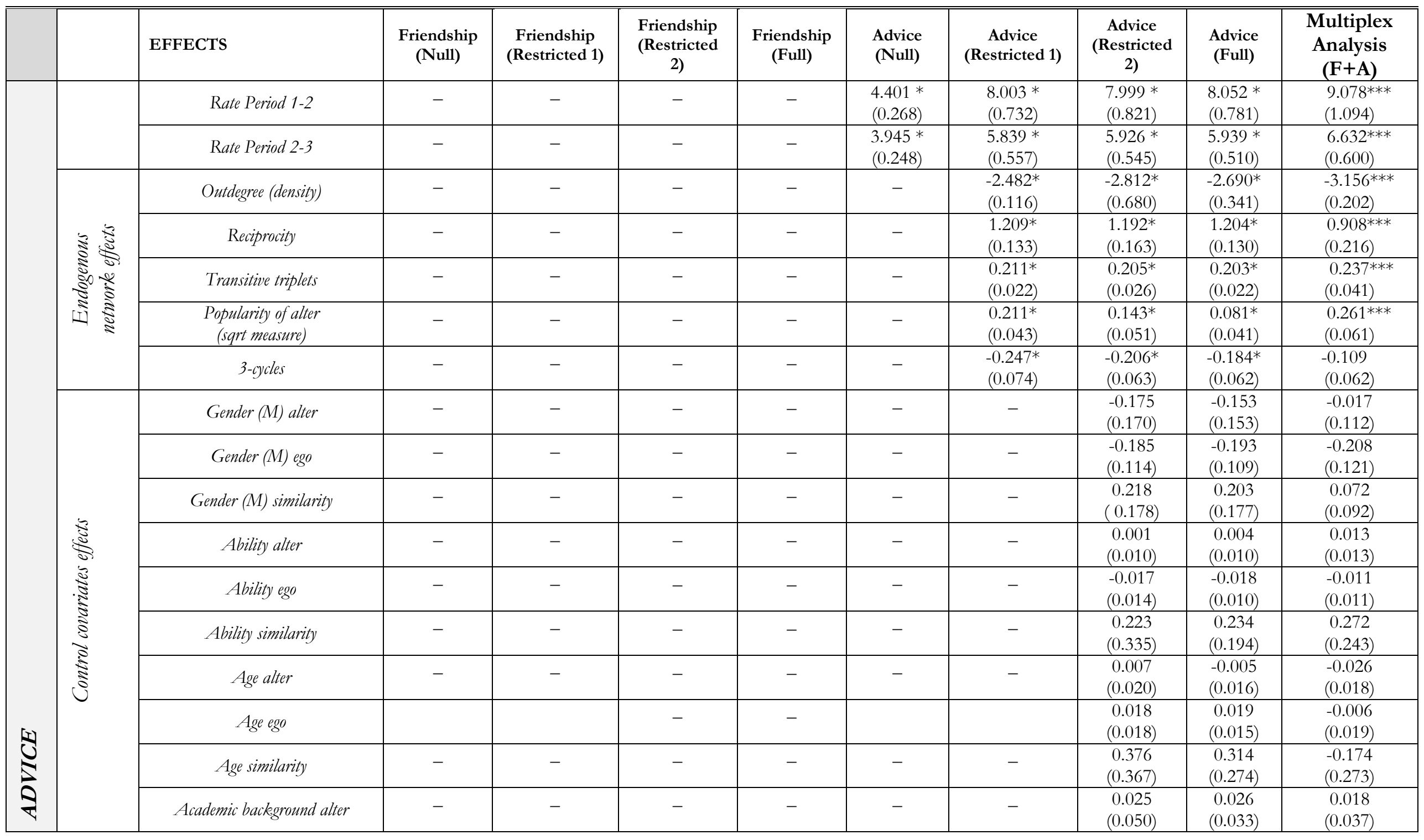




\begin{tabular}{|c|c|c|c|c|c|c|c|c|c|c|}
\hline & Academic background ego & - & - & - & - & - & - & $\begin{array}{c}0.020 \\
(0.059) \\
\end{array}$ & $\begin{array}{c}0.019 \\
(0.035) \\
\end{array}$ & $\begin{array}{c}0.003 \\
(0.036) \\
\end{array}$ \\
\hline & Academic background similarity & - & - & - & - & - & - & $\begin{array}{l}0.419^{*} \\
(0.184)\end{array}$ & $\begin{array}{l}0.409^{*} \\
(0.181)\end{array}$ & $\begin{array}{l}0.393^{*} \\
(0.193)\end{array}$ \\
\hline & Work experience alter & - & - & - & - & - & - & $\begin{array}{c}0.151 \\
(0.096) \\
\end{array}$ & $\begin{array}{c}0.112 \\
(0.095) \\
\end{array}$ & $\begin{array}{c}0.030 \\
(0.118) \\
\end{array}$ \\
\hline & Work experience ego & - & - & - & - & - & - & $\begin{array}{c}0.061 \\
(0.095) \\
\end{array}$ & $\begin{array}{c}0.086 \\
(0.094) \\
\end{array}$ & $\begin{array}{c}0.089 \\
(0.111) \\
\end{array}$ \\
\hline & Work experience similarity & - & - & - & - & - & - & $\begin{array}{c}0.136 \\
(0.081)\end{array}$ & $\begin{array}{c}0.133 \\
(0.078)\end{array}$ & $\begin{array}{c}0.133 \\
(0.097)\end{array}$ \\
\hline & Nationality alter & - & - & - & - & - & - & $\begin{array}{l}-0.164 \\
(0.286)\end{array}$ & $\begin{array}{l}-0.183 \\
(0.173)\end{array}$ & $\begin{array}{c}0.155 \\
(0.191)\end{array}$ \\
\hline & Nationality ego & - & - & - & - & - & - & $\begin{array}{l}-0.102 \\
(0.875) \\
\end{array}$ & $\begin{array}{l}-0.087 \\
(0.316) \\
\end{array}$ & $\begin{array}{l}-0.102 \\
(0.184) \\
\end{array}$ \\
\hline & Nationality similarity & - & - & - & - & - & - & $\begin{array}{c}0.236 \\
(0.779) \\
\end{array}$ & $\begin{array}{c}0.264 \\
(0.337) \\
\end{array}$ & $\begin{array}{l}0.362^{*} \\
(0.170)\end{array}$ \\
\hline & Performance alter & - & - & - & - & - & - & $\begin{array}{l}0.126^{*} \\
(0.057)\end{array}$ & $\begin{array}{l}0.092^{*} \\
(0.042)\end{array}$ & $\begin{array}{l}0.114^{*} \\
(0.047)\end{array}$ \\
\hline & Performance ego & - & - & - & - & - & - & $\begin{array}{l}-0.106 \\
(0.085) \\
\end{array}$ & $\begin{array}{l}-0.091^{*} \\
(0.043)\end{array}$ & $\begin{array}{l}-0.125^{*} \\
(0.059) \\
\end{array}$ \\
\hline & Performance similarity & - & - & - & - & - & - & $\begin{array}{c}0.765 \\
(0.491) \\
\end{array}$ & $\begin{array}{l}0.762^{*} \\
(0.264)\end{array}$ & $\begin{array}{l}0.810^{*} \\
(0.345)\end{array}$ \\
\hline है & Status alter & - & - & - & - & - & - & - & $\begin{array}{l}0.020^{*} \\
(0.010)\end{array}$ & $\begin{array}{l}0.020^{*} \\
(0.010)\end{array}$ \\
\hline$\frac{3}{5}$ & Status ego & - & - & - & - & - & - & - & $\begin{array}{l}-0.006 \\
(0.010) \\
\end{array}$ & $\begin{array}{c}0.008 \\
(0.011) \\
\end{array}$ \\
\hline 芠 & Status similarity & - & - & - & - & - & - & - & $\begin{array}{c}0.188 \\
(0.390)\end{array}$ & $\begin{array}{c}0.342 \\
(0.385) \\
\end{array}$ \\
\hline & Friendship: Advice & - & - & - & - & - & - & - & - & $\begin{array}{l}1.729^{* * *} \\
(0.260)\end{array}$ \\
\hline  & Advice: Friendship & - & - & - & - & - & - & - & - & $\begin{array}{l}1.306^{* * *} \\
(0.138)\end{array}$ \\
\hline
\end{tabular}

$* \mathrm{p}<0.05$. 
Table 7a - Influence of friends on log odds of status increase compared to status decrease, if all friends have the same status (Status $[\min , \max ]=[1,31]$ ).

\begin{tabular}{|c|c|c|c|}
\hline \multirow{4}{*}{$\underset{80}{8}$} & & \multicolumn{2}{|c|}{ Alter } \\
\hline & & Low & High \\
\hline & Low & 0.03 & 0.46 \\
\hline & High & 1.05 & 1.44 \\
\hline
\end{tabular}

Table $\mathbf{7 b}$ - Influence of advisors on log odds of status increase compared to status decrease, if all advisors have the same status (Status $[\min , \max ]=[1,31]$ )

\begin{tabular}{|c|c|c|c|}
\hline \multirow{4}{*}{$\begin{array}{c}8 \\
80 \\
{[I}\end{array}$} & & \multicolumn{2}{|c|}{ Alter } \\
\hline & & Low & High \\
\hline & Low & 0.06 & 0.95 \\
\hline & High & -0.53 & 0.78 \\
\hline
\end{tabular}

